\title{
MicroRNA-494-3p protects rat cardiomyocytes against septic shock via PTEN
}

\author{
PENG WU, LINGCHEN KONG and JIANZHONG LI \\ Intensive Medicine Department, Linyi Central Hospital, Linyi, Shandong 276400, P.R. China
}

Received December 6, 2017; Accepted July 26, 2018

DOI: $10.3892 / \mathrm{etm} .2018 .7116$

\begin{abstract}
The aim of the present study was to investigate the role of microRNA (miR)-494-3p in myocardial injury in patients with septic shock and the underlying mechanism. A total of 22 patients with sepsis and 17 patients with septic shock were included in the present study. In addition, 20 healthy subjects were recruited as the control group. Peripheral blood was collected from all subjects and a rat cardiomyocyte model of myocardial injury was constructed. Reverse transcription-quantitative polymerase chain reaction was used to measure miR-494-3p expression, while cell counting kit- 8 assays were performed to assess cell proliferation. Flow cytometry was performed to investigate cell cycle distribution and apoptosis. Lactate dehydrogenase (LDH) assays were performed to measure LDH levels. ELISA was also performed to measure LDH, tumor necrosis factor (TNF)- $\alpha$ and interleukin (IL)-6 levels in cell culture supernatants. Western blotting was employed to detect phosphatase and tensin homolog (PTEN) protein expression and dual luciferase reporter assays were performed to identify the interaction between miR-494-3p and PTEN mRNA. Reduced miR-494-3p expression was correlated with myocardial damage in patients with septic shock. Sera from patients with septic shock downregulated miR-494-3p expression in rat cardiomyocytes. miR-494-3p overexpression inhibited rat cardiomyocyte injury induced by treatment with sera from patients with septic shock. Furthermore, miR-494-3p overexpression reduced the synthesis and release of TNF- $\alpha$ and IL-6 from rat cardiomyocytes. PTEN knockdown alleviated rat cardiomyocyte injury following treatment with serum from patients with septic shock. PTEN was demonstrated to induce the release of TNF- $\alpha$ and IL- 6 from rat cardiomyocytes treated with septic shock serum, while miR-494-3p was demonstrated to bind to the 3'-untranslated seed region of PTEN mRNA to regulate its expression. The results of the
\end{abstract}

Correspondence to: Dr Jianzhong Li, Intensive Medicine Department, Linyi Central Hospital, 17 Jiankang Road, Linyi, Shandong 276400, P.R. China

E-mail:wup112233@163.com

Key words: microRNA-494-3p, myocardial injury, rat cardiomyocytes, septic shock, phosphatase and tensin homolog present study suggest that miR-494-3p is downregulated in the peripheral blood of patients with septic shock and is negatively correlated with myocardial injury. The present study also indicates that miR-494-3p regulates PTEN expression, inhibits sepsis-induced myocardial injury and protects the function of cardiomyocytes. The protective effect and mechanism of action of miR-494-3p indicate that it has potential for use in the clinical diagnosis and therapy of myocardial damage.

\section{Introduction}

Septic shock is a serious clinical syndrome that typically develops as a result of infection-induced sepsis $(1,2)$. Large-scale microorganism invasion will cause a stress reaction in tissues and organs. Moderate stress responses may enhance the defensive capacity of the body and control the spread of infection (3); however, prolonged exposure to pathogens can aggravate tissue/organ damage, particularly following a stress reaction (4,5). During septic shock, damaged tissues and organs stimulate the release of large amounts of inflammatory mediators, including tumor necrosis factor (TNF)- $\alpha$ and interleukin (IL)-6, from inflammatory cells, which aggravates the inflammatory response (6). Septic shock is often accompanied by organ dysfunction and tissue hypoperfusion. If it is not treated in a timely manner, septic shock is able to induce acute circulatory failure, resulting in patient mortality $(7,8)$. An epidemiological study suggested that the mortality rate of patients with septic shock is high at $>40 \%$ (9). With modern medicine, the prognosis of patients with septic shock has improved significantly (10). However, treating septic shock is dependent on improving the balance of the internal physiological environment inside and outside of cells, to reduce inflammation and prevent organ damage (11).

It has previously been reported that multiple organ failure is the typical cause of mortality in patients with septic shock and symptoms of the disease include low perfusion of organs and an inability to maintain normal metabolic functions $(12,13)$. Cardiac systolic and diastolic functions are directly associated with the prognosis of patients with septic shock $(14,15)$. It has previously been reported that endotoxins and inflammatory factors in the peripheral blood of patients with septic shock are the main causes of myocardial injury (16). Cardiomyocytes synthesize cytokines, including TNF- $\alpha$, aggravate myocardial injury, upregulate cytokine receptor expression and participate in the pathogenesis of septic shock (17). In view of the important 
roles of cytokines in septic shock-induced myocardial injury, researchers have attempted to use cytokine antagonists as a treatment for patients with septic shock $(18,19)$. However, the effect of single cytokines is limited, as the inflammatory response of septic shock is described as a cascade $(20,21)$. Therefore, improving our understanding of the molecular mechanism of myocardial injury in septic shock may be of great significance when developing novel treatments.

MicroRNA (miRNA or miR) is a class of endogenous, highly conserved non-coding RNA molecules 18-22 nucleotides in length (22). miRNAs inhibit the translation of proteins by binding to the 3'-untranslated region (UTR) of mRNAs (23). miRNAs are stable in body fluids, making them suitable biomarkers for diseases (24). Previous studies have demonstrated that a variety of miRNAs are associated with the myocardial injury repair, including miR-210 and miR-214 $(25,26)$, suggesting that miRNAs serve important roles in the diagnosis and treatment of myocardial injury. miR-494-3p is a novel cardiovascular and tumor-associated miRNA that serves important roles in tumor proliferation, invasion and metastasis (27). It has been reported that miR-494-3p is associated with the regulation of vascular injury and repair, as well as regulation of the phosphatase and tensin homolog (PTEN), phosphoinositide 3-kinase (PI3K) and mammalian target of rapamycin (mTOR) signaling pathways (28). PTEN is located on chromosome 10q23.3 and comprises 9 exons (29). It encodes a protein 403 amino acids in length and has phosphatase activity (30). It has been reported that PTEN is able to inhibit the development of tumors by antagonizing tyrosine kinase and other phosphorylases responsible for angiogenesis, cell survival and other biological processes (31). PTEN is also associated with the $\mathrm{PI} 3 \mathrm{~K} /$ protein kinase B (AKT) signaling pathway (32). In the present study, the role of miR-494-3p in myocardial injury in patients with septic shock was investigated. The aim was to provide an experimental basis for the diagnosis and treatment of septic shock-induced myocardial injury.

\section{Patients and methods}

Patients. A total of 22 patients with sepsis and 17 patients with septic shock were included in the present study. Patients were excluded from the current study if they possessed any tumor, diabetes, autoimmune diseases or a had a history of taking certain medication, including thyroxine. All patients were treated at Intensive Medicine Department, Linyi Central Hospital (Linyi, China) between December 2016 and March 2017. Among the 39 patients (22 with sepsis, 17 with septic shock), 29 were male and 10 were female. The age range was $38-58$ years. Among the 22 patients with sepsis, 18 were male and 4 were female (age range, 38-53 years); among the 17 patients with septic shock, 11 were male and 6 were female (age range, 40-51 years). In addition, 20 healthy subjects (10 male and 10 female; age range, 35-48 years) who underwent physical examinations at the same hospital and time period were included as a control group. Peripheral blood $(5 \mathrm{ml})$ was collected from all subjects at the start of the study. Samples were centrifuged at a speed of $12,000 \mathrm{x} \mathrm{g}$ at $4^{\circ} \mathrm{C}$ for $10 \mathrm{~min}$ to separate serum and were stored at $-80^{\circ} \mathrm{C}$. Clinical information and pathological data of all patients were collected (data not shown). All experimental procedures were approved by the Ethics Committee of Linyi Central Hospital. Written informed consent was obtained from all patients or their families.

Cells. Rat cardiomyocytes (M6200; ScienCell Research Laboratories, Inc., San Diego, CA, USA) were divided into the negative control (NC) group, sepsis serum group and septic shock serum group and cultured in 24-well plates (1x10 $/$ well) containing Cardiac Myocyte Medium (CMM; cat. no. 6101; ScienCell Research Laboratories, Inc.) at $37^{\circ} \mathrm{C}$ in an atmosphere containing $5 \% \mathrm{CO}_{2}$. When cells reached 70-90\% confluence, the medium was replaced by a mixture of $250 \mu \mathrm{l}$ sepsis patient serum or septic shock patient serum and $250 \mu \mathrm{l}$ fresh CMM medium and incubated at $37^{\circ} \mathrm{C}$ in an atmosphere containing $5 \% \mathrm{CO}_{2}$ for $24 \mathrm{~h}$. Cells in the control group were treated with a mixture of $250 \mu \mathrm{l}$ serum from healthy subjects and $250 \mu \mathrm{l}$ fresh CMM medium for the same duration.

At 1 day prior to transfection, $2 \times 10^{5}$ purchased cardiomyocytes were seeded in 24-well plates containing serum-free CMM medium. When cells reached $70 \%$ confluence, transfection was performed. In the first vial, $1.5 \mu \mathrm{lmiR}-494-3 \mathrm{p}$ mimics (5'-TGAAACATACACGGGAAACCTC-3'; $20 \mathrm{pmol} / \mu \mathrm{l}$; HanBio Biotechnology Co., Ltd., Shanghai, China) or miR-NC (cat. no. miR01201-1-5; 20 pmol/ $\mu$ l; HanBio Biotechnology Co., Ltd.) was mixed with $50 \mu \mathrm{l}$ Opti Mem medium (Thermo Fisher Scientific, Inc., Waltham, MA, USA). In the second vial, $1 \mu 1$ Lipofectamine ${ }^{\circledR} 3000$ (Thermo Fisher Scientific, Inc.) was mixed with $50 \mu \mathrm{l}$ Opti Mem medium. Following incubation at room temperature for $5 \mathrm{~min}$, the two vials were combined and incubated at room temperature for $20 \mathrm{~min}$. Cells were subsequently treated with this mixture at $37^{\circ} \mathrm{C}$ and $5 \% \mathrm{CO}_{2}$ for $6 \mathrm{~h}$, following which the medium was replaced with CMM medium containing 10\% fetal bovine serum (Thermo Fisher Scientific, Inc.). For further assays, cells were then incubated at $37^{\circ} \mathrm{C}$ in an atmosphere containing $5 \% \mathrm{CO}_{2}$ for $48 \mathrm{~h}$ prior to collection via digestion with trypsin and centrifugation at $1,000 \mathrm{x} \mathrm{g}$ at room temperature for $5 \mathrm{~min}$.

At 1 day prior to transfection, $2 \times 10^{5} \mathrm{M} 6200$ cardiomyocytes were seeded into 24-well plates containing serum-free Cardiac Myocyte Medium (CMM; cat. no. 6101; ScienCell Research Laboratories, Inc.). When cells reached $70 \%$ confluence, transfection was performed. In the first vial, $1.5 \mu \mathrm{l}$ siR-PTEN (5'-AAC CCACCACAGCUAGAACTT-3') or siR-NC (5'-TTCTCCGAA CGTGTCACGTTT-3'; 20 pmol/ $\mu$ l; HanBio Biotechnology Co., Ltd., Shanghai, China) was mixed with $50 \mu 1$ Opti Mem medium (Thermo Fisher Scientific, Inc.), respectively. In the second vial, $1 \mu 1$ Lipofectamine ${ }^{\circledR} 3000$ (Thermo Fisher Scientific, Inc.) was mixed with $50 \mu \mathrm{l}$ Opti Mem medium. Following incubation for $5 \mathrm{~min}$, the two vials were combined and incubated at room temperature for $20 \mathrm{~min}$. Cells were subsequently incubated for $6 \mathrm{~h}$, following which the medium was replaced with CMM containing $10 \%$ fetal bovine serum. Cells were then incubated at $37^{\circ} \mathrm{C}$ in an atmosphere containing $5 \% \mathrm{CO}_{2}$ for $48 \mathrm{~h}$ prior to collection for further assays.

Reverse transcription-quantitative polymerase chain reaction $(R T-q P C R)$. Peripheral blood $(250 \mu 1)$ was lysed with $750 \mu 1$ TRIzol LS isolation reagent (Thermo Fisher Scientific, Inc.). Total RNA was extracted using the phenol 
chloroform method (33). The purity of RNA was determined by A260/A280 using UV-spectrophotometry (Nanodrop ND2000; Thermo Fisher Scientific, Inc.). cDNA was obtained by $\mathrm{RT}$ at $42^{\circ} \mathrm{C}$ for 30 min using the PrimeScript RT Regent kit (Takara Biotechnology Co., Ltd., Dalian, China) according to the manufacturer's protocol and stored at $-20^{\circ} \mathrm{C}$. PCR was performed using the SYBR PrimeScript RT-PCR Kit (Takara Biotechnology Co., Ltd.), with U6 forward, 5'-CTCGCT TCGGCAGCACA-3' and reverse, 5'-AACGCTTCACGA ATTTGCGT-3' as an internal reference. The reaction system (20 $\mu \mathrm{l})$ comprised RT-qPCR-mix $(10 \mu \mathrm{l})$, upstream primer (0.5 $\mu \mathrm{l})\left(\mathrm{miR}-494-3 \mathrm{p}, 5^{\prime}\right.$-TGAAACATACACGGGAAACCT C-3'; U6, 5'-CTCGCTTCGGCAGCACA-3'), downstream universal primer $(0.5 \mu \mathrm{l}$; provided with the kit), cDNA $(2 \mu \mathrm{l})$ and $\mathrm{ddH}_{2} \mathrm{O}(7 \mu \mathrm{l})$. Thermocycling conditions were as follows: Initial denaturation at $95^{\circ} \mathrm{C}$ for $10 \mathrm{~min}$ followed by 40 cycles of $95^{\circ} \mathrm{C}$ for $1 \mathrm{~min}$ and $60^{\circ} \mathrm{C}$ for $30 \mathrm{sec}$ (StepOnePlus Real-Time PCR System; Thermo Fisher Scientific, Inc.). The $2^{-\Delta \Delta C q}$ method (34) was used to calculate the relative expression of miR-494-3p against the internal reference. Each sample was tested in triplicate.

Cell Counting kit (CCK)-8 assay for cell proliferation. Cells (serum treatment groups, miRNA transfection groups and interference groups) were seeded at a density of 3,000 cells/well in 96-well plates and cultured in $\mathrm{CMM}$ at $37^{\circ} \mathrm{C}$ in an atmosphere containing $5 \% \mathrm{CO}_{2}$. At 0, 24, 48 and $72 \mathrm{~h}, 20 \mu \mathrm{l} \mathrm{CCK}-8$ ( $5 \mathrm{~g} / \mathrm{l}$; Beyotime Institute of Biotechnology, Haimen, China) was added to the cells prior to incubation at $37^{\circ} \mathrm{C}$ and $5 \% \mathrm{CO}_{2}$ for $2 \mathrm{~h}$. Subsequently, $150 \mu \mathrm{l}$ CCK-8 reaction solution was added and cells were incubated at $37^{\circ} \mathrm{C}$ for $2 \mathrm{~h}$. The absorbance of each well was measured at $490 \mathrm{~nm}$ to construct cell proliferation curves. Each group was tested in triplicate.

Flow cytometry. Cells $\left(1 \times 10^{6}\right)$ from each group were washed twice with precooled PBS and subjected to flow cytometry using a Cell Cycle Assay kit (BD Biosciences, Franklin Lakes, NJ, USA) according to the manufacturer's protocol. Cell cycle distribution was analyzed using ModFit software (version 5.0; Verity Software House, Topsham, ME, USA).

Following treatment with sera from healthy subjects, patients with sepsis or patients with septic shock for $24 \mathrm{~h}$, cells $\left(1 \times 10^{6}\right)$ from each group were washed with precooled PBS twice and subjected to flow cytometry using an Annexin V fluorescein (FITC) Apoptosis Detection kit I (BD Biosciences; included PI staining materials) according to the manufacturers protocol. Cells with Annexin V-positive staining were early apoptotic cells, those with propidium iodide (PI)-positive values were necrotic and double-positive values were cells in late apoptosis. ModFit software (version 5.0; Verity Software House, Inc., Topsham, ME, USA) was used for the analysis of results.

Lactate dehydrogenase ( $L D H)$ assay. Cells were seeded in 24 -well plates at a density of $2 \times 10^{5}$ cells/well and incubated with serum from healthy subjects, patients with sepsis or patients with septic shock at $37^{\circ} \mathrm{C}$ for $24 \mathrm{~h}$. Then, medium was replaced with fresh $\mathrm{CMM}$ medium, followed by incubation at $37^{\circ} \mathrm{C}$ for $6 \mathrm{~h}$. The supernatant was collected by centrifugation at $12,000 \mathrm{x} \mathrm{g}$ and $4^{\circ} \mathrm{C}$ for $10 \mathrm{~min}$. A total of $120 \mu \mathrm{l}$ supernatant was used for the LDH assay according to the manufacturer's protocol (cat. no. C0016; Beyotime Institute of Biotechnology). Absorbance was measured at $490 \mathrm{~nm}$ by a reader (SpectraMax; Molecular Devices, LLC, Sunnyvale, CA, USA).

ELISA. LDH, TNF- $\alpha$ (cat. no. ab208348) and IL-6 (cat. no. ab100712) ELISA kits (Abcam, Cambridge, UK) were used to measure serum LDH, TNF- $\alpha$ and IL-6. Standards (50 $\mu \mathrm{l})$ and samples $(10 \mu \mathrm{l}$ serum and $40 \mu \mathrm{l}$ diluent, provided by the kits) were added to predefined microplate wells, while the blank well was left empty. Horseradish peroxidase (HRP)-labeled conjugates (100 $\mu \mathrm{l}$; provided by the kit) were added to wells prior to sealing for incubation at $37^{\circ} \mathrm{C}$ for $1 \mathrm{~h}$. Plates were washed five times, following which substrates A $(50 \mu \mathrm{l})$ and $\mathrm{B}(50 \mu \mathrm{l})$ were added into each well. Following incubation at $37^{\circ} \mathrm{C}$ for $15 \mathrm{~min}$, stop solution (50 $\left.\mu \mathrm{l}\right)$ was added and the absorbance of each well was measured at $450 \mathrm{~nm}$. Each sample was tested in triplicate.

Western blot analysis. Cells $\left(1 \times 10^{6}\right)$ from each group were trypsinized and collected via centrifugation at a speed of $1,000 \mathrm{x} \mathrm{g}$ for $5 \mathrm{~min}$ at room temperature. Precooled radioimmunoprecipitation assay buffer $(1,000 \mu \mathrm{l}$; Beyotime Institute of Biotechnology) was added to the samples. Phenylmethane sulfonyl fluoride $(1 \mathrm{mM})$ was used as a protease inhibitor. Following lysis for $30 \mathrm{~min}$ on ice, the mixture was centrifuged at $10,000 \mathrm{x} \mathrm{g}$ and $4^{\circ} \mathrm{C}$ for $10 \mathrm{~min}$. Proteins were quantified using a bicinchoninic acid protein concentration determination kit (RTP7102; Real-Times Beijing Biotechnology Co., Ltd., Beijing, China). Protein samples were mixed with 5X SDS loading buffer (Beyotime Institute of Biotechnology) prior to denaturation in boiling water for $10 \mathrm{~min}$. Samples $(20 \mu \mathrm{g})$ were separated using $10 \%$ SDS-PAGE gels. Resolved proteins were transferred to polyvinylidene difluoride membranes on ice $(100 \mathrm{~V} ; 1 \mathrm{~h})$ and blocked with $5 \%$ skimmed milk at room temperature for $1 \mathrm{~h}$. Membranes were subsequently incubated with rabbit anti-human PTEN (1:1,000; cat. no. ab32199), rabbit anti-human IL-6 (1:1,000; cat. no. ab6672), rabbit anti-human TNF- $\alpha$ (1:800; cat. no. ab6671) and mouse anti-human GAPDH (1:4,000; cat. no. ab8245; all Abcam) polyclonal primary antibodies at $4^{\circ} \mathrm{C}$ overnight. Following extensive washing with PBS with Tween 20 (PBST) five times for $5 \mathrm{~min}$, membranes were incubated with goat anti-rabbit $(1: 4,000$; cat. no. A0208) or goat anti-mouse (1:4,000; cat. no. A0216; all Abcam) HRP-conjugated secondary antibodies for $1 \mathrm{~h}$ at room temperature. Membranes were washed with PBST five times for $5 \mathrm{~min}$ and developed using an enhanced chemiluminescence detection kit (Sigma-Aldrich; Merck KGaA, Darmstadt, Germany) for imaging. Image lab v3.0 software (Bio-Rad Laboratories, Inc., Hercules, CA, USA) was used to acquire and analyze imaging signals. Relative PTEN expression was measured against GAPDH. Each test was performed in triplicate.

Dual luciferase reporter assay. Based on the results of a Targetscan search (v7.1; http://www.targetscan.org), wild-type (WT) and mutant seed regions of miR-494-3p in the 3'-UTR of the PTEN gene were chemically synthesized in vitro, with SpeI and HindIII restriction sites and cloned 
A

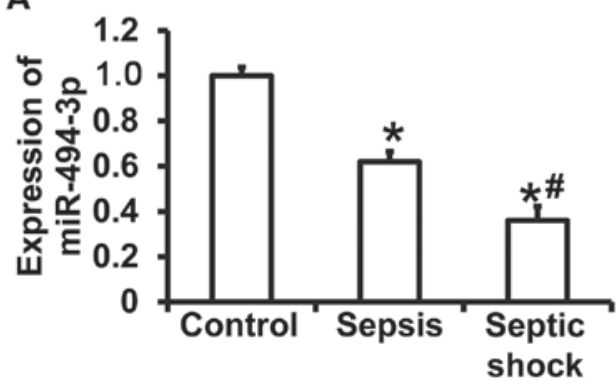

B

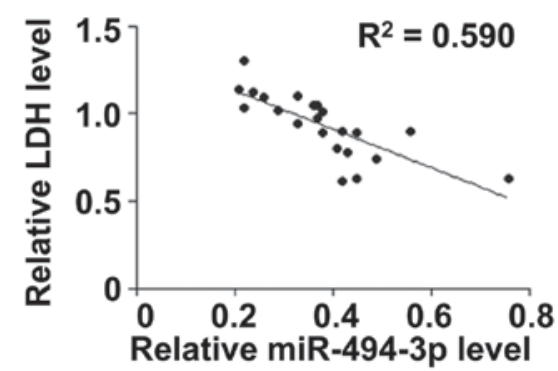

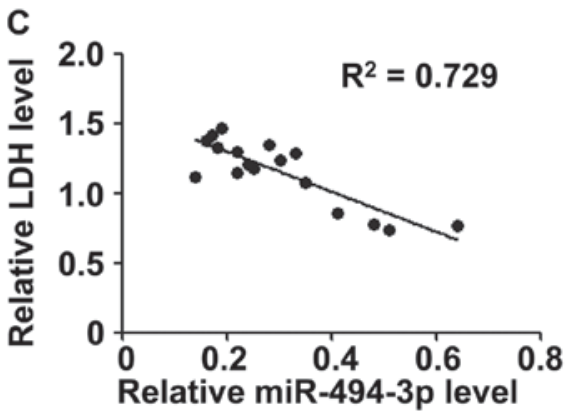

Figure 1. Correlation between miR-494-3p and LDH expression in the peripheral blood. (A) Peripheral miR-494-3p expression in healthy subjects, patients with sepsis and patients with septic shock. Correlation between miR-494-3p and LDH expression in patients with (B) sepsis and (C) septic shock. * $<0.05$ vs. control; ${ }^{\text {"}} \mathrm{P}<0.05$ vs. patients with sepsis. miR, microRNA; LDH, lactate dehydrogenase.

into pMIR-REPORT luciferase reporter plasmids (Beyotime Institute of Biotechnology). Plasmids $(0.5 \mu \mathrm{g} ; 20 \mathrm{pmol} / \mu \mathrm{l})$ with WT or mutant 3'-UTR DNA sequences were co-transfected with miR-494-3p mimics (20 pmol/ $\mu \mathrm{l})$ into 293T cells (Type Culture Collection of the Chinese Academy of Sciences, Shanghai, China) using Lipofectamine ${ }^{\circledR} 3000$ (Thermo Fisher Scientific, Inc.). Following cultivation for $24 \mathrm{~h}$, cells were lysed using a dual luciferase reporter assay kit (Promega Corporation, Madison, WI, USA) according to the manufacturer's protocol and the fluorescence intensity was measured using a GloMax 20/20 luminometer (Promega Corporation). Renilla fluorescence activity was used as internal reference. Each test was performed in triplicate.

Statistical analysis. Results were analyzed using SPSS 17.0 statistical software (SPSS, Inc., Chicago, IL, USA). Data are expressed as the mean \pm standard deviation. Multiple group comparisons were analyzed using one-way analysis of variance followed by Student Newman-Keuls post-hoc test. Spearman's correlation analysis was performed to evaluate the correlation between miR-494-3p and LDH levels. $\mathrm{P}<0.05$ was considered to indicate a statistically significant difference.

\section{Results}

Reduced miR-494-3p expression in peripheral blood is correlated with myocardial damage in patients with septic shock. RT-qPCR results revealed that miR-494-3p levels were significantly decreased in patients with sepsis and patients with septic shock compared with healthy subjects $(\mathrm{P}<0.05)$ (Fig. 1A). In addition, miR-494-3p levels were significantly decreased in patients with septic shock compared with patients with sepsis $(\mathrm{P}<0.05)$ (Fig. 1A). ELISA was performed to measure serum LDH and the data suggested a correlation between miR-494-3p and LDH in patients with sepsis (correlation coefficient, 0.590; $\mathrm{P}<0.05$ ) (Fig. 1B) and in patients with septic shock (correlation coefficient, 0.729; $\mathrm{P}<0.05$ ) (Fig. 1C). The results suggest that reduced miR-494-3p expression is associated with myocardial damage in patients with septic shock.

Serum from patients with septic shock downregulates miR-494-3p expression in rat cardiomyocytes. RT-qPCR results revealed that miR-494-3p was significantly decreased in rat cardiomyocytes incubated with serum from patients with sepsis or patients with septic shock were compared with those incubated with serum from healthy subjects $(\mathrm{P}<0.05)$ (Fig. 2A). No significant differences were observed in miR-494-3p expression between rat cardiomyocytes incubated with serum from patients with sepsis or serum from patients with septic shock $(\mathrm{P}>0.05)$ (Fig. 2A). Furthermore, the absorbance of rat cardiomyocytes incubated with serum from patients with septic shock or patients with sepsis for $48 \mathrm{~h}$ or $72 \mathrm{~h}$ was significantly decreased compared with the control group $(\mathrm{P}<0.05)$ (Fig. 2B). Cell cycle analysis demonstrated that the percentage of cells in $\mathrm{G}_{1}$ phase was significantly increased in the sepsis serum and septic shock serum groups compared with the control group $(\mathrm{P}<0.05)$ (Fig. 2C), while there was no significant difference between the sepsis serum and the septic shock serum groups ( $>>0.05)$ (Fig. 2C). The apoptosis rate of rat cardiomyocytes in the septic shock serum group was significantly increased compared with the sepsis serum and control groups $(\mathrm{P}<0.05)$ (Fig. 2D), while apoptosis was significantly increased in the sepsis serum group compared with the control group $(\mathrm{P}<0.05)$ (Fig. 2D). The results indicated that serum from patients with septic shock downregulated miR-494-3p expression in rat cardiomyocytes.

miR-494-3p overexpression inhibits rat cardiomyocyte injury induced by serum from septic shock patients. To further 

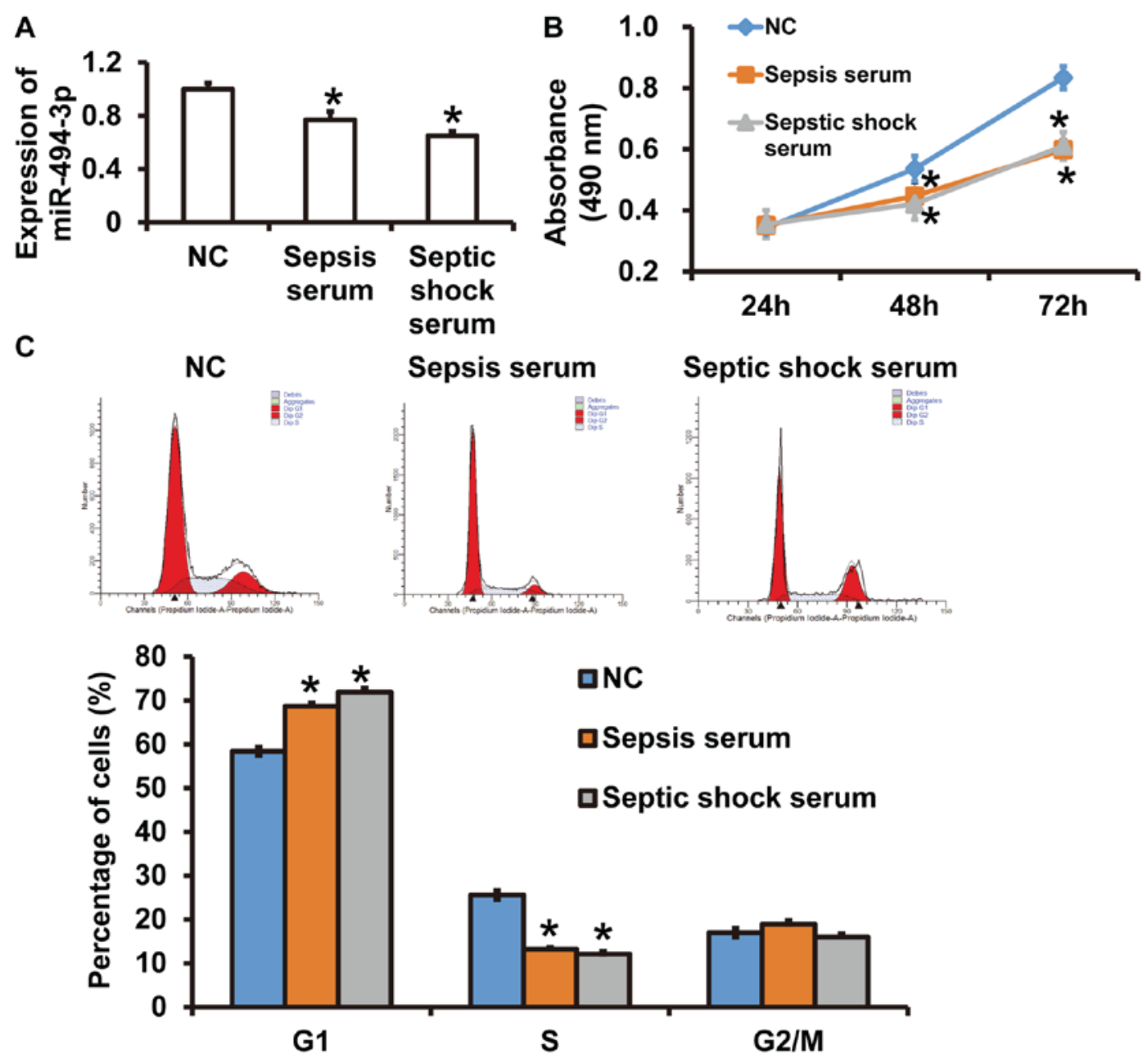

D
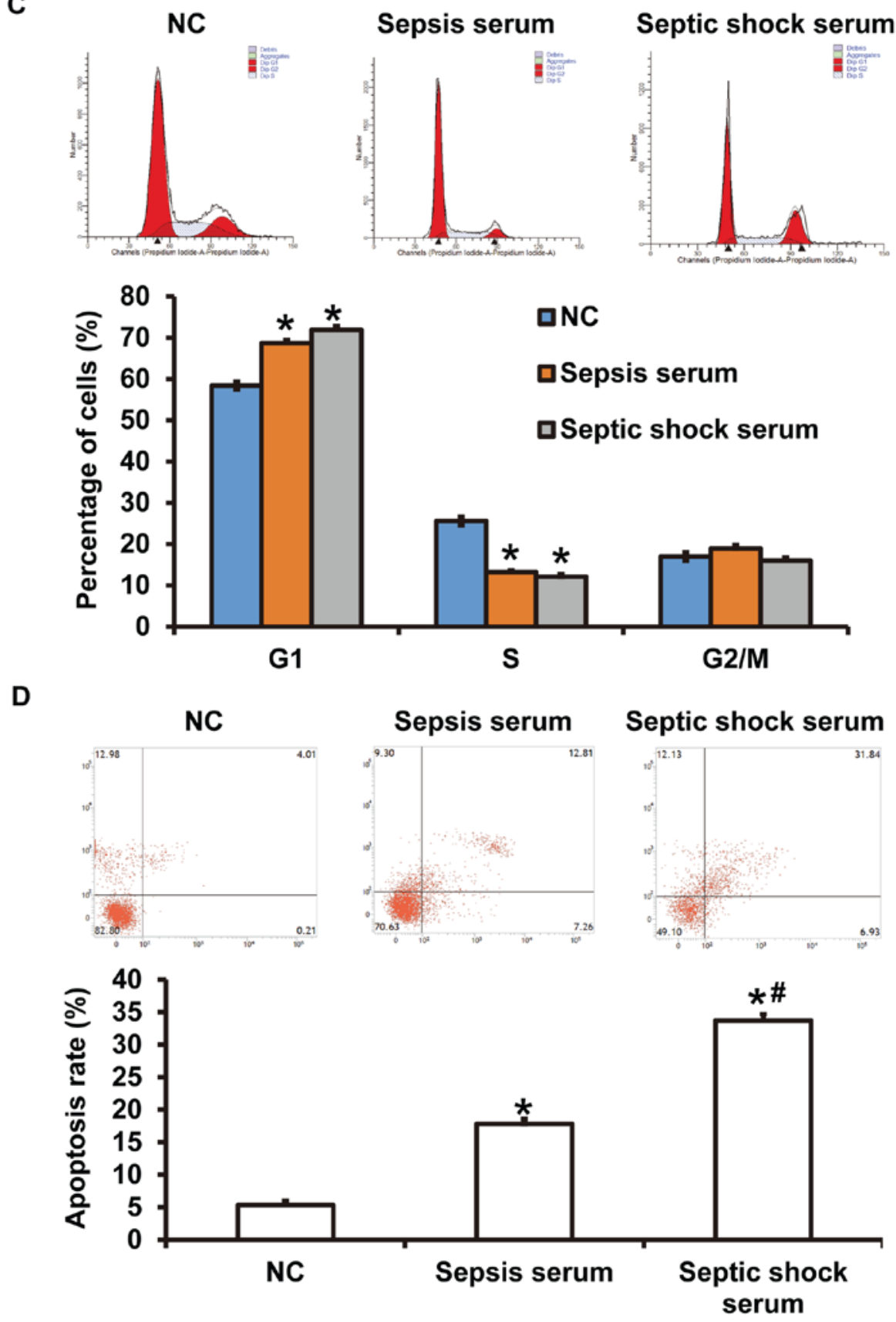

Figure 2. Effects of patient sera on miR-494-3p expression in rat cardiomyocytes. Rat cardiomyocytes were incubated with sera from healthy control subjects, patients with sepsis or patients with septic shock. (A) miR-494-3p expression in rat cardiomyocytes. (B) Proliferation was measured using cell counting kit-8 assays. Absorbance at $490 \mathrm{~nm}$ was recorded following incubation for 24, 48 or $72 \mathrm{~h}$. (C) Cell cycle distribution and (D) apoptosis rates were assessed using flow cytometry. ${ }^{*} \mathrm{P}<0.05$ vs. $\mathrm{NC}$; ${ }^{\mathrm{P}} \mathrm{P}<0.05$ vs. sepsis serum group. $\mathrm{NC}$, healthy control; miR, microRNA.

investigate the effect of miR-494-3p on serum-induced cardiomyocyte injury, rat cardiomyocytes that were treated with serum from patients with septic shock were transfected with miR-NC and miR-494-3p sequences, using untreated cardiomyocytes as blank control. RT-qPCR revealed that miR-494-3p expression was significantly increased in cells 

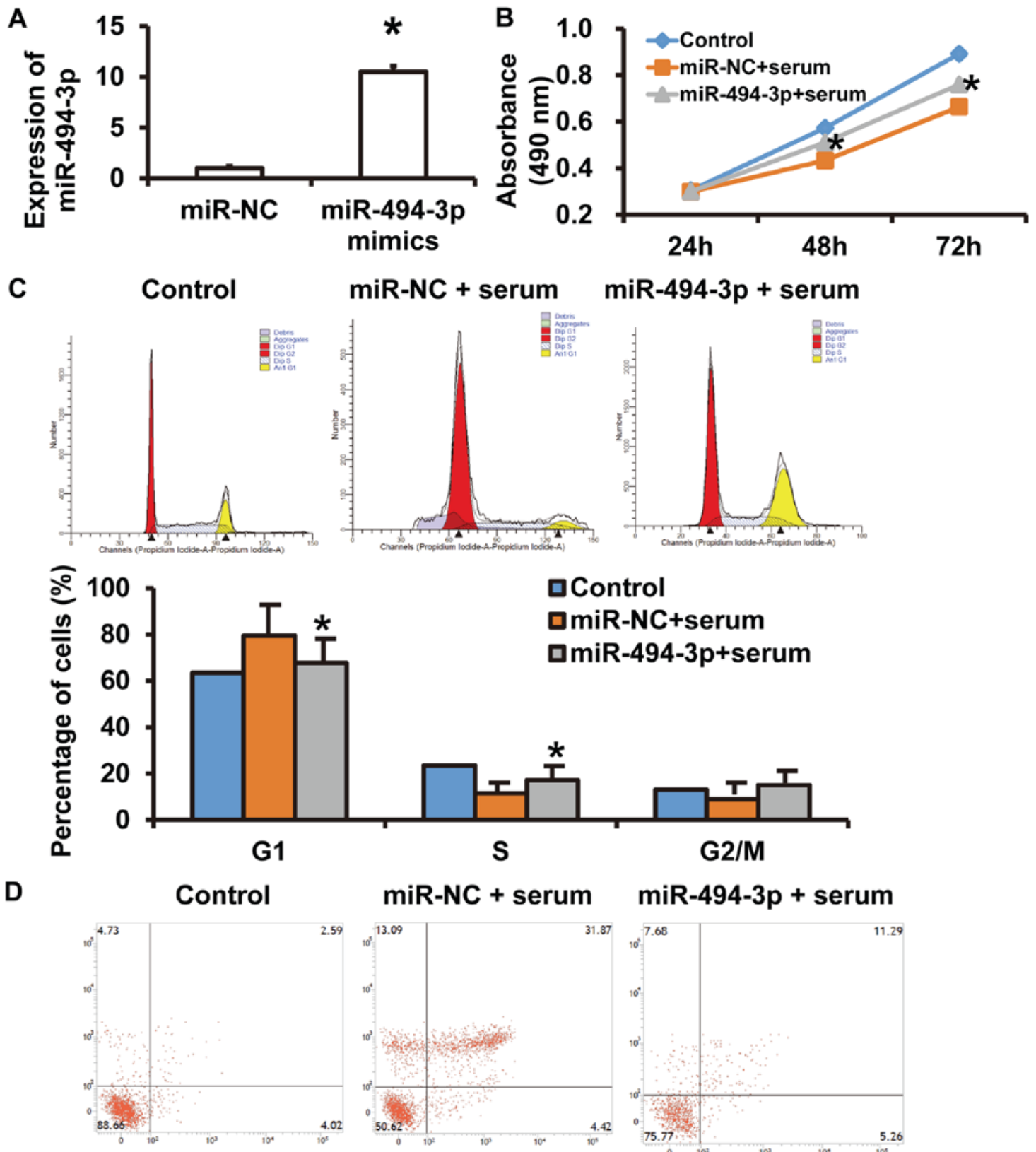

\section{口Control \\ 口miR-NC+serum \\ 口miR-494-3p+serum}

D
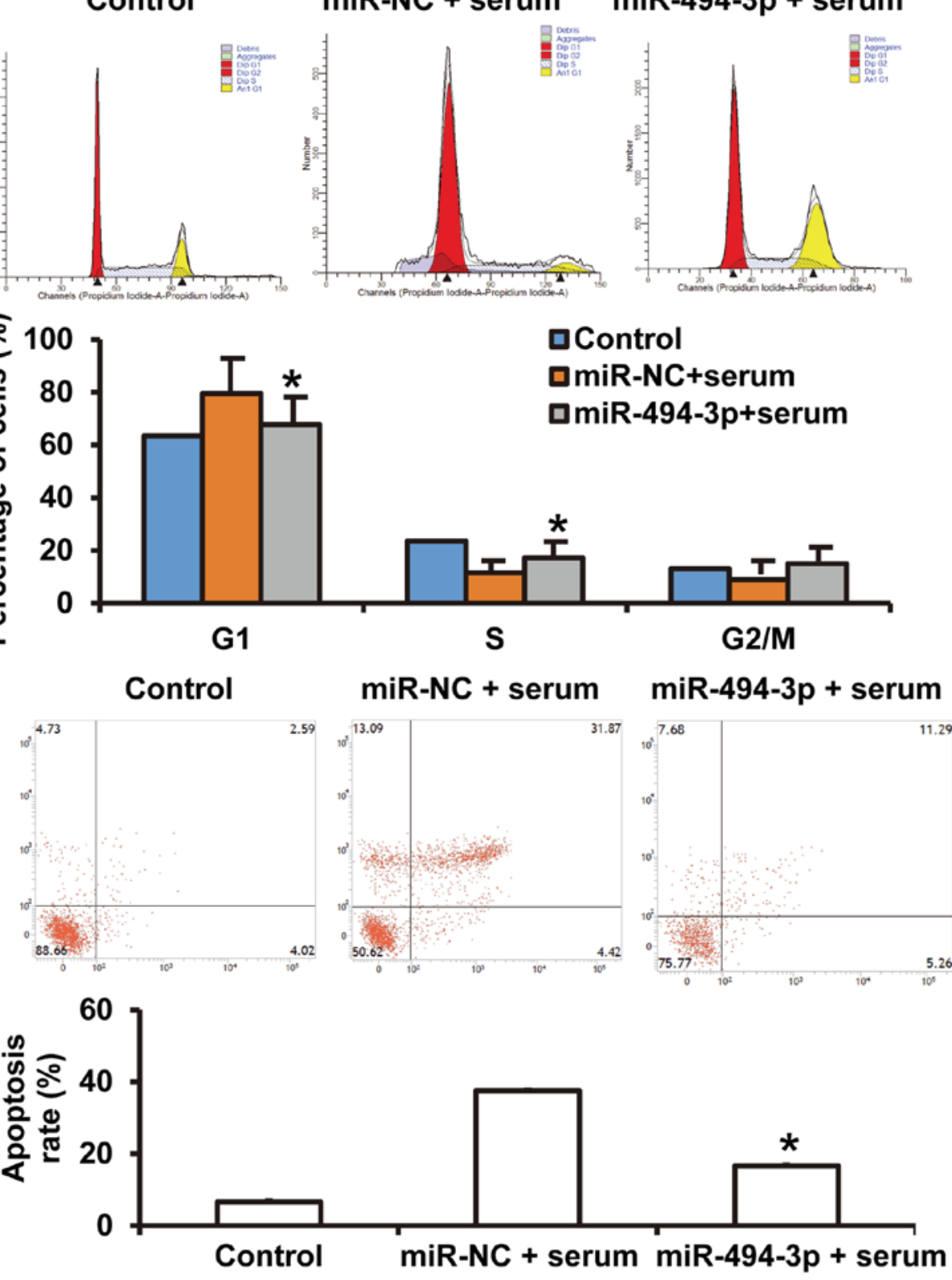

Figure 3. Effect of miR-494-3p on rat cardiomyocyte injury induced by septic shock serum. Rat cardiomyocytes were transfected with miR-NC or miR-494-3p mimics and incubated with septic shock serum. (A) miR-494-3p expression. (B) Proliferation was assessed using a cell counting kit-8 assay. Absorbance at $490 \mathrm{~nm}$ was recorded following incubation for 24,48 or $72 \mathrm{~h}$. (C) Cell cycle analysis and (D) apoptosis rates were assessed using flow cytometry. ${ }^{*} \mathrm{P}<0.05$ vs. miR-NC group. miR, microRNA; NC, negative control.

transfected with miR-494-3p compared with the miR-NC group $(\mathrm{P}<0.05)$ (Fig. 3A). CCK-8 assays revealed that the absorbance of septic shock serum-treated rat cardiomyocytes transfected with miR-494-3p was significantly increased compared with serum-treated cells in the miR-NC group at 48 and $72 \mathrm{~h}(\mathrm{P}<0.05)$ (Fig. 3B). In addition, the percentage of cells in the $\mathrm{G}_{1}$ phase was significantly decreased in the miR-494-3p-transfected serum-treated group compared with the miR-NC-transfected serum-treated group $(\mathrm{P}<0.05)$ (Fig. 3C). The number of apoptotic cells in the miR-494-3p + serum group was significantly reduced compared with the miR-NC + serum group $(\mathrm{P}<0.05)($ Fig. 3D). 
A

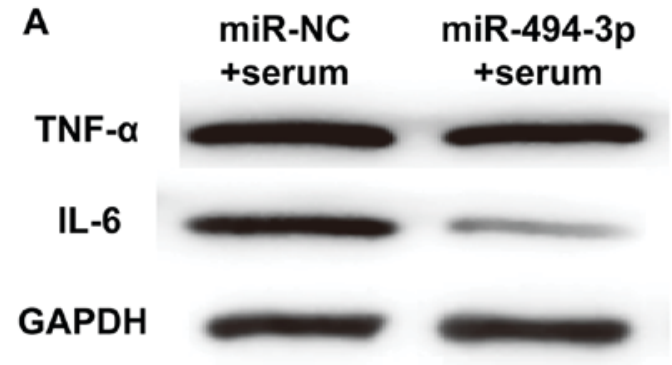

B

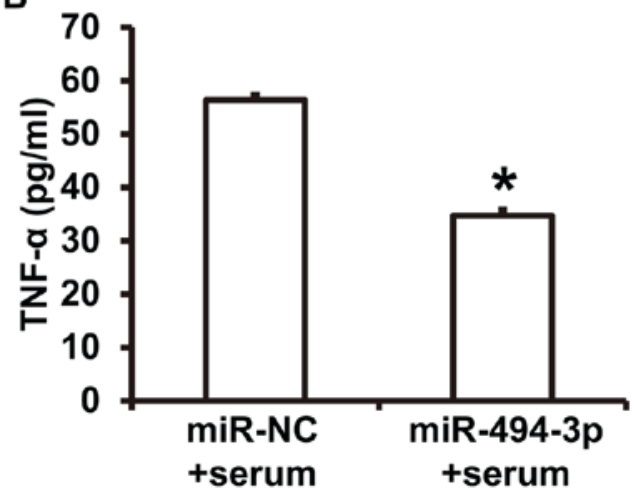

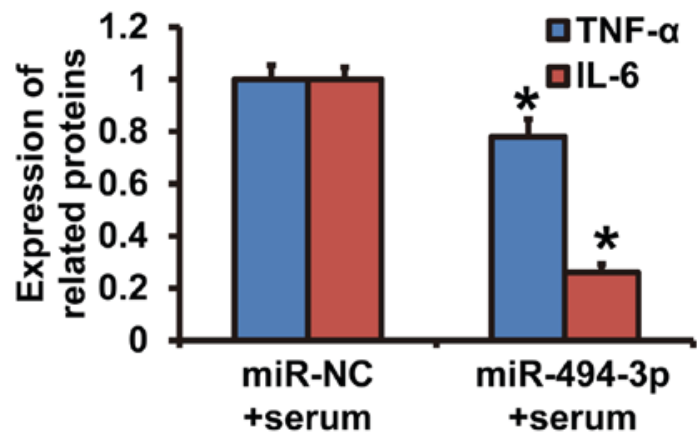

C

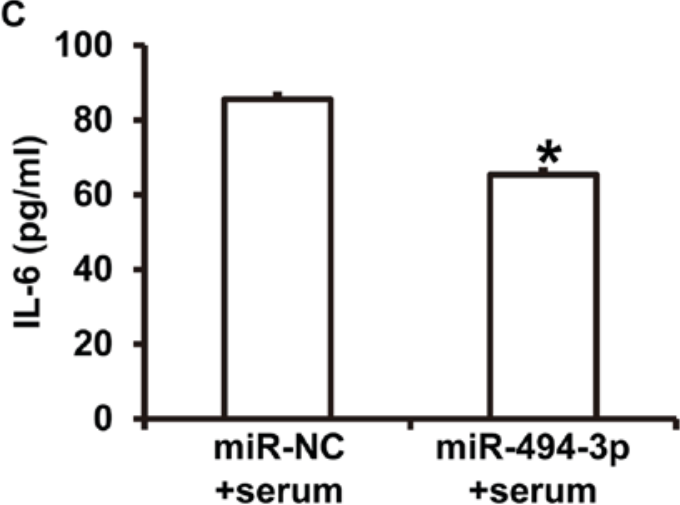

Figure 4. Effect of miR-494-3p on the synthesis and release of cytokines. Rat cardiomyocytes were transfected with miR-NC or miR-494-3p mimics following incubation with septic shock serum. (A) TNF- $\alpha$ and IL-6 protein expression was measured using western blotting. Concentrations of (B) TNF- $\alpha$ and (C) IL-6 in the culture supernatant were determined using ELISA. * $\mathrm{P}<0.05$ vs. miR-NC group. miR, microRNA; TNF- $\alpha$, tumor necrosis factor- $\alpha$; IL-6, interleukin-6; $\mathrm{NC}$, negative control.

These results suggest that miR-494-3p overexpression protects rat cardiomyocytes against injury induced by sera from patients with septic shock.

miR-494-3p expression reduces the synthesis and release of $T N F-\alpha$ and IL-6 in ratcardiomyocytes. Western blotting revealed that TNF- $\alpha$ and IL- 6 expression was significantly decreased in cardiomyocytes in the miR-494-3p + serum group compared with the miR-NC + serum group $(\mathrm{P}<0.05)$ (Fig. 4A). ELISA results revealed that TNF- $\alpha$ and IL- 6 concentrations in culture supernatants from cardiomyocytes in the miR-494-3p + serum group were significantly decreased compared with the miR-NC + serum group $(\mathrm{P}<0.05)$ (Fig. 4B and $\mathrm{C})$. The results indicated that miR-494-3p expression reduced the synthesis and release of TNF- $\alpha$ and IL-6 from rat cardiomyocytes.

PTEN knockdown alleviates injuries of rat cardiomyocytes that are induced by septic shock serum. To identify the target gene of miR-494-3p, TargetScan was used. It was revealed that PTEN was a target gene for miR-494-3p (Fig. 5A). To detect of PTEN expression, western blotting was performed. The results demonstrated that the greyscale value of PTEN from rat cardiomyocytes transfected with miR-494-3p was significantly lower compared with the in miR-NC group $(\mathrm{P}<0.05)$ (Fig. 5B). Western blotting revealed that PTEN expression was significantly decreased in cardiomyocytes treated with siR-PTEN compared with the siR-NC group $(\mathrm{P}<0.05)$ (Fig. 5C). CCK-8 assays revealed that the absorbance of cardiomyocytes was significantly increased in the siR-PTEN group compared with the siR-NC group at 48 and $72 \mathrm{~h}$ $(\mathrm{P}<0.05)$ (Fig. 5D), reaching a level similar to cardiomyocytes cultured under normal conditions (control) ( $\mathrm{P}>0.05)$ (Fig. 5D). Cell cycle analysis suggested that the percentage of cells in $\mathrm{G}_{1}$ phase in the siR-PTEN group was significantly decreased compared with the siR-NC group $(\mathrm{P}<0.05)$ (Fig. 5E). Flow cytometry demonstrated that siR-PTEN treatment significantly decreased the apoptotic rate compared with the siR-NC group $(\mathrm{P}<0.05)$ (Fig. 5F). LDH assay results revealed that LDH levels were significantly decreased in the culture supernatant from cardiomyocytes in the siR-PTEN group compared with the siR-NC group $(\mathrm{P}<0.05)$ (Fig. 5G). The LDH level in control group was too low and so was excluded from the figure. The results suggested that PTEN knockdown alleviated septic shock serum-induced injuries in rat cardiomyocytes.

PTEN triggers TNF- $\alpha$ and IL-6 release from rat cardiomyocytes treated with septic shock serum. To investigate how PTEN affects the release of cytokines, ELISA was performed. The results demonstrated that TNF- $\alpha$ and IL-6 levels were significantly decreased in the culture supernatant of the siR-PTEN group compared with the siR-NC group $(\mathrm{P}<0.05)$ (Fig. 6A and B). The results indicate that PTEN promotes the release of TNF- $\alpha$ and IL-6 from rat cardiomyocytes treated with septic shock serum.

miR-494-3p binds to the 3 '-UTR of PTEN $m R N A$ to regulate its expression. To assess the interaction between miR-494-3p and the 3'-UTR of PTEN mRNA, dual luciferase reporter assays were performed. The fluorescence value of cells cotransfected with miR-494-3p mimics and pMIR-REPORT-WT luciferase reporter plasmids was significantly decreased compared with the negative control group for WT $(\mathrm{P}<0.05)$ (Fig. 7). In contrast, the fluorescence value of cells cotransfected with 
A

5' ...ggguUuUgauUuUganuguUuca... PTEN

| || || || | || ||

3' CUCCAAAGGGCACA----UACAAAGU miR-494-3p

B
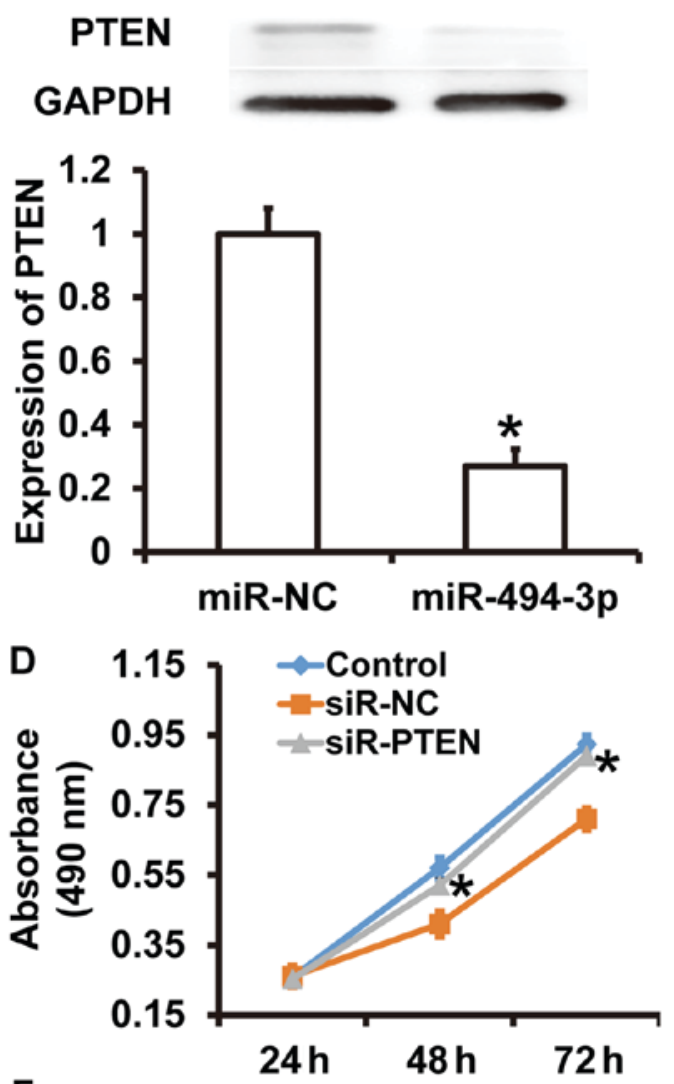

F

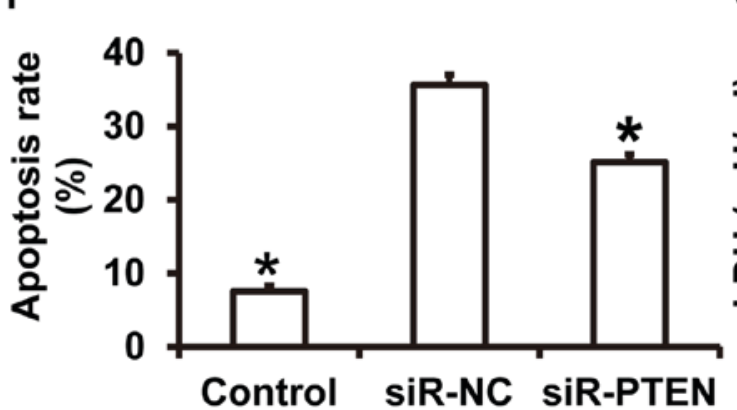

C
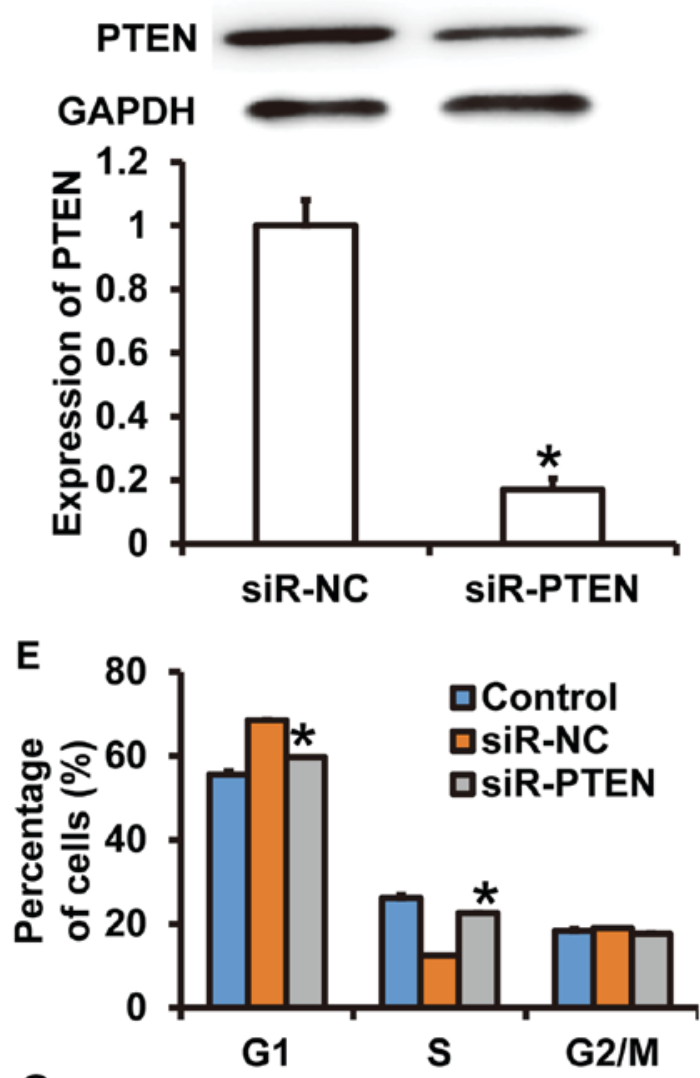

G

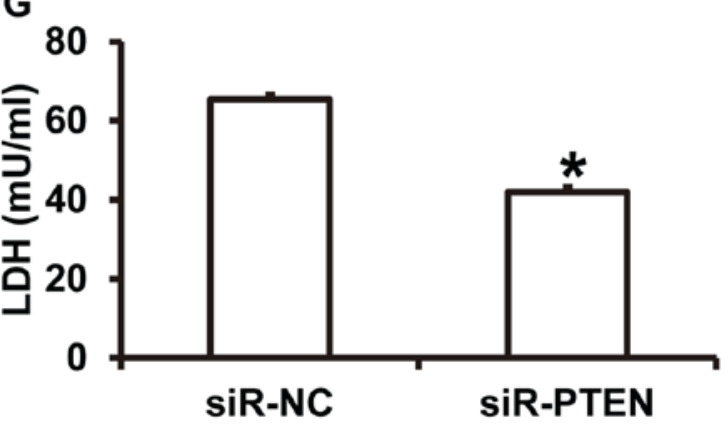

Figure 5. Effect of PTEN on rat cardiomyocyte injury induced by septic shock serum. (A) Bioinformatics prediction of binding sites between miR-494-3p and PTEN mRNA. Western blots of PTEN in rat cardiomyocytes transfected with (B) miR-NC, miR-494-3p mimics, (C) siR-NC or siR-PTEN. Effect of PTEN overexpression on (D) proliferation, (E) cell cycle distribution, (F) apoptosis and (G) LDH expression. * P<0.05 vs. siR-NC group. Control, cardiomyocytes cultured under normal conditions; miR, microRNA; NC, negative control; siR, short interfering RNA; PTEN, phosphatase and tensin homolog; LDH, lactate dehydrogenase.

miR-494-3p mimics and pMIR-REPORT-mutant luciferase reporter plasmid was not significantly different compared with the negative control group for mutant $(\mathrm{P}>0.05)$ (Fig. 7). The results suggest that miR-494-3p binds to the 3'-UTR of PTEN mRNA to regulate expression.

Discussion

Septic shock is a common acute disease that occurs secondary to sepsis and is typically caused by microbial infection (35). Patients with septic shock often suffer from multiple organ damage, while decreased systolic and diastolic capacity resulting from myocardial cell injury can lead to microcirculatory perfusion disorder, accelerate the multiple organ failure and seriously affect the prognosis of the patients (36). The mechanism of myocardial injury in patients with septic shock is not fully understood, although it has been suggested that this process mainly includes myocardial cell proliferation inhibition, as well as increased apoptosis and inflammation (37). miRNAs are an important 
A

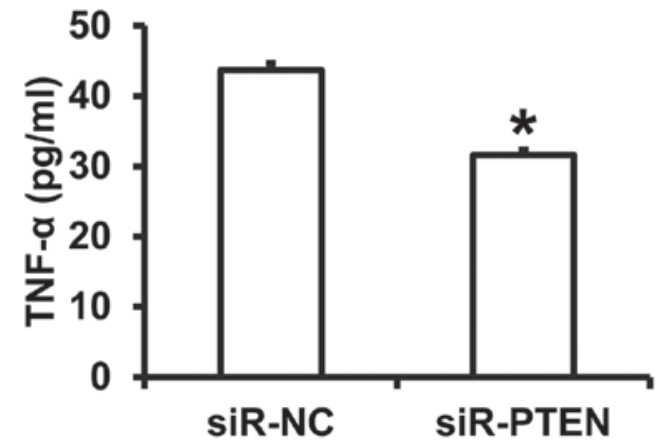

B

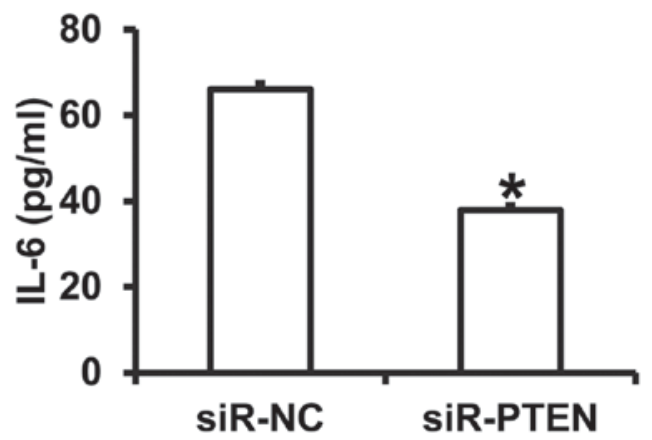

Figure 6. Effect of PTEN expression on cytokine expression. Serum concentrations of (A) TNF- $\alpha$ and (B) IL-6 were measured using ELISA for rat cardiomyocytes treated with septic shock serum and transfected with siR-NC or siR-PTEN. ${ }^{*}<0.05$ vs. siR-NC group. PTEN, phosphatase and tensin homolog; TNF- $\alpha$, tumor necrosis factor- $\alpha$; IL-6, interleukin-6; siR, short interfering RNA; NC, negative control.

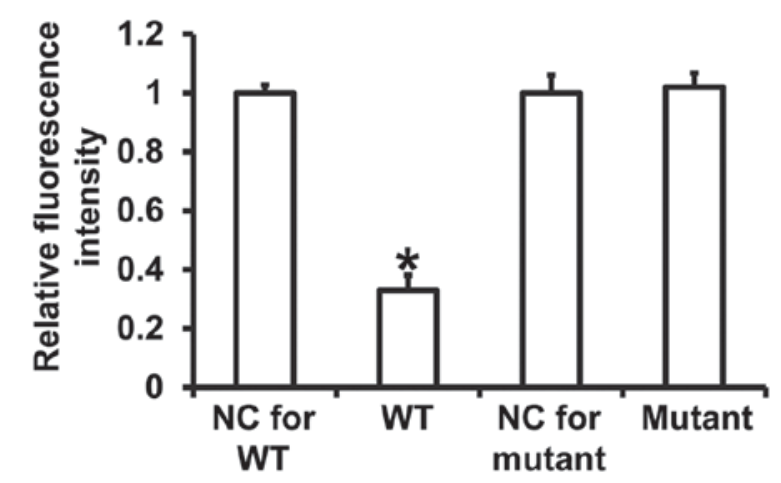

Figure 7. Interactions between miR-494-3p and PTEN mRNA. Plasmids with wild type or mutant PTEN sequences were cotransfected into 293T cells with miR-494-3p mimics. Following 24 h cultivation, dual luciferase reporter assays were performed using Renilla as the internal reference. ${ }^{*} \mathrm{P}<0.05$ vs. NC group of wild-type (WT) or mutant. miR, microRNA; PTEN, phosphatase and tensin homolog; NC, negative control.

class of posttranscriptional regulatory factors that participate in numerous pathophysiological processes (38). Septic shock results in a type of hypoperfusion-induced ischemia reperfusion injury regulated by a variety of miRNAs (39). miR-142-3p inhibits hypoxia/reoxygenation-induced myocardial cell injury by targeting the high mobility group box 1 gene (39). In addition, miR-378 protects intestinal tissues by inhibiting the apoptosis of intestinal epithelial cells and resisting ischemia reperfusion injury (40). miR-494-3p is a novel miRNA that serves important roles in the occurrence and development of tumors (41). It has been reported that miR-494-3p inhibits hepatic ischemia-reperfusion injury by activating the PI3K/AKT signaling pathway (42). In the present study, it was evaluated whether miR-494-3p serves a role in septic shock-induced myocardial injury. The results revealed that miR-494-3p expression was reduced in patients with septic shock and was negatively correlated with LDH levels, a marker of myocardial injury. This suggests that miR-494-3p may be associated with myocardial injury. At the cellular level, incubation with sera from patients with septic shock downregulated miR-494-3p expression in rat cardiomyocytes and promoted the release of LDH into cell culture supernatants. Functional experiments demonstrated that sera from patients with septic shock inhibited the proliferation of rat cardiomyocytes and promoted apoptosis and inflammation in rat cardiomyocytes. Furthermore, serum from patients with septic shock stimulated the synthesis and release of TNF- $\alpha$ and IL- 6 from rat cardiomyocytes. Rescue experiments revealed that miR-493-3p overexpression ameliorates the effects of septic shock serum treatment on proliferation and apoptosis in rat cardiomyocytes. miR-494-3p overexpression also stimulated the release of LDH, TNF- $\alpha$ and IL-6 into the culture supernatants of rat cardiomyocytes. These results suggest that miR-493-3p has a protective effect on cardiomyocytes.

In the present study, bioinformatics analysis suggested that miR-494-3 may target and regulate PTEN. It has been reported that miR-494-3p serves a role in regulating PTEN expression in tumors and ischemia-reperfusion injury (43). The results presented in the current study suggest that miR-494-3p downregulates PTEN protein expression. Additionally, dual luciferase reporter assays confirmed that miR-494-3p directly binds to the 3'-UTR of PTEN.

In conclusion, the present study revealed that miR-494-3p downregulation in the peripheral blood of patients with septic shock is correlated with myocardial injury. miR-494-3p promotes proliferation and inhibits apoptosis in cardiomyocytes, as well as stimulating the synthesis and release of cytokines. miR-494-4p overexpression alleviates myocardial cell injury and may be used as a potential diagnostic and therapeutic target. The small sample size used in the present study is a limitation, and future studies should be performed to confirm these findings.

\section{Acknowledgements}

The authors would like to thank President Zhigang Zhang and Director Wenhong Peng of the Linyi Central Hospital for their support and instructions.

\section{Funding}

No funding was received.

\section{Availability of data and materials}

The datasets used and/or analyzed during the current study are available from the corresponding author on reasonable request. 


\section{Authors' contributions}

PW and JL designed the current study. PW and LK performed experiments. PW, LK and JL analyzed the data. All authors collaborated to interpret results and develop the manuscript. The final version of the manuscript was read and approved by all authors, and each author believes that the manuscript represents honest work.

\section{Ethics approval and consent to participate}

All experimental procedures were approved by the Ethics Committee of Linyi Central Hospital. Written informed consent was obtained from all patients or their families.

\section{Patient consent for publication}

Not applicable.

\section{Competing interests}

The authors declare that they have no competing interests.

\section{References}

1. Liu Y, Wan W, Fang F, Guo L, Zhao Y, Zhang X and Huang F: Clinical relevance of peroxisome proliferator-activated receptor-gamma gene polymorphisms with sepsis. J Clin Lab Anal 32: e22340, 2018.

2. Zhou X, Ding B, Ye Y, Tang G and Zhang Z: An appropriate mean arterial pressure (MAP) does not always mean hemodynamic stability in septic shock patients. J Crit Care 43: 397-398, 2017.

3. Santos-Junior MN, Rezende IS, Souza CLS, Barbosa MS, Campos GB, Brito LF, Queiroz ÉC, Barbosa EN, Teixeira MM, Da Silva LO, et al: Ureaplasma diversum and its membrane-associated lipoproteins activate inflammatory genes through the NF- $\mathrm{BB}$ pathway via toll-like receptor 4 . Front Microbiol 9: 1538, 2018.

4. Zasada M, Lenart M, Rutkowska-Zapala M, Stec M, Durlak W, Grudzień A, Krzeczkowska A, Mól N, Pilch M, Siedlar M and Kwinta P: Analysis of PD-1 expression in the monocyte subsets from non-septic and septic preterm neonates. PLoS One 12 e0186819, 2017.

5. Xu LY and Xu D: Changes in blood oxygen metabolism indices and their clinical significance in children with septic shock. Zhongguo Dang Dai Er Ke Za Zhi 19: 1124-1128, 2017 (In Chinese).

6. Dargent A, Nguyen M, Fournel I, Bourredjem A, Charles PE, Quenot JP and the EPISS study group: Vasopressor cumulative dose requirement and risk of early death during septic shock: An analysis from the episs cohort. Shock 49: 625-630, 2018.

7. Sharawy N, Mahrous R, Whynot S, George R and Lehmann C: Clinical relevance of early sublingual microcirculation monitoring in septic shock patients. Clin Hemorheol Microcirc 68 347-359, 2018

8. Park JS, Choi HS, Yim SY and Lee SM: Heme oxygenase-1 protects the liver from septic injury by modulating tLR4-mediated mitochondrial quality control in mice. Shock 50: 209-218, 2018

9. Ding W and Jiang L: The Effects of afebrile characteristic on patients with suspected septic shock: Several facts need to be noticed. Crit Care Med 45: e1191, 2017.

10. Kim YC, Song JE, Kim EJ, Choi H, Jeong WY, Jung IY, Jeong SJ, Ku NS, Choi JY, Song YG and Kim JM: A simple scoring system using the red blood cell distribution width, delta neutrophil index, and platelet count to predict mortality in patients with severe sepsis and septic shock. J Intensive Care Med 1: 885066618787448, 2018.

11. Vazquez-Guillamet MC, Vazquez R, Micek ST and Kollef MH: Predicting resistance to piperacillin-tazobactam, cefepime and meropenem in septic patients with bloodstream infection due to gram-negative bacteria. Clin Infect Dis 65: 1607-1614, 2017.
12. Erwin BL, Denaburg MA, Barker AB, McArdle PJ, Windham ST and Morgan CJ: Evaluation of vasopressin for septic shock in patients on chronic renin-angiotensin-aldosterone system inhibitors. Crit Care Med 45: e1226-e1232, 2017.

13. Hyvernat H, Doyen D, Barel R, Kaidomar M, Goubaux B, Pradier C, Panaïa-Ferrari P, Dellamonica J and Bernardin G: Is inappropriate response to cosyntropin stimulation test an indication of corticosteroid resistance in septic shock? Shock 498: 543-550, 2018

14. Makara MA, Hoang KV, Ganesan LP, Crouser ED, Gunn JS, Turner J, Schlesinger LS, Mohler PJ and Rajaram MV: Cardiac electrical and structural changes during bacterial infection: An instructive model to study cardiac dysfunction in sepsis. J Am Heart Assoc 5: e003820, 2016.

15. Martin L, Peters C, Schmitz S, Moellmann J, Martincuks A, Heussen N, Lehrke M, Müller-Newen G, Marx G and Schuerholz T: Soluble heparan sulfate in serum of septic shock patients induces mitochondrial dysfunction in murine cardiomyocytes. Shock 44: 569-577, 2015.

16. Huang L, Zheng M, Zhou Y, Zhu J, Zhu M, Zhao F and Cui S: Tanshinone IIA attenuates cardiac dysfunction in endotoxin-induced septic mice via inhibition of NADPH oxidase 2-related signaling pathway. Int Immunopharmacol 28: 444-449, 2015.

17. Feng Y, Zou L, Chen C, Li D and Chao W: Role of cardiac- and myeloid-MyD88 signaling in endotoxin shock: A study with tissue-specific deletion models. Anesthesiology 121: 1258-1269, 2014.

18. Kimura A, Kitajima M, Nishida K, Serada S, Fujimoto M, Naka T, Fujii-Kuriyama Y, Sakamato S, Ito T, Handa $\mathrm{H}$, Tanaka T, et al: NQO1 inhibits the TLR-dependent production of selective cytokines by promoting I $\kappa \mathrm{B}-\zeta$ degradation. J Exp Med 215: 2197-2209, 2018.

19. Gu X, Wei C, Zhu X, Lu F, Sheng B and Zang X: Effect of interleukin-31 on septic shock through regulating inflammasomes and interleukin-1 $\beta$. Exp Ther Med 16: 171-177, 2018.

20. Li T, Sun XZ, Lai DH, Li X and He YZ: Fever and systemic inflammatory response syndrome after retrograde intrarenal surgery: Risk factors and predictive model. Kaohsiung J Med Sci1 34: 400-408, 2018.

21. Kawamoto E, Masui-Ito A, Eguchi A, Soe ZY, Prajuabjinda O, Darkwah S, Park EJ, Imai $\mathrm{H}$ and Shimaoka $\mathrm{M}$ : Integrin and PD-1 ligand expression on circulating extracellular vesicles in systemic inflammatory response syndrome and sepsis. Shock, 2018. (Epub ahead of print).

22. Zhao W, Shen G, Ren H, Liang, Yu X, Zhang Z, Huang J, Qiu T, Tang J, Shang Q, et al: Therapeutic potential of microRNAs in osteoporosis function by regulating the biology of cells related to bone homeostasis. J Cell Physiol, 2018. (Epub ahead of print).

23. Kanthaje S, Makol A and Chakraborti A: Sorafenib response in hepatocellular carcinoma: MicroRNAs as tuning forks miRNAs as regulators of sorafenib response in HCC. Hepatol Res 38: 5-14: 2018 .

24. Thyagarajan A, Shaban A and Sahu RP: miRNA directed cancer therapies: Implications in melanoma intervention. J Pharmacol Exp Ther 364: 1-12, 2018.

25. Ge C, Liu J and Dong S: MIRNA-214 protects sepsis-induced myocardial injury. Shock 50: 112-118, 2018.

26. Diao H, Liu B, Shi Y, Song C, Guo Z, Liu N, Song X, Lu Y, Lin X and Li Z: MicroRNA-210 alleviates oxidative stress-associated cardiomyocyte apoptosis by regulating BNIP3. Biosci Biotechnol Biochem 81: 1712-1720, 2017.

27. Salati S, Salvestrini V, Carretta C, Genovese E, Rontauroli S, Zini R, Rossi C, Ruberti S, Bianchi E, Barbieri G, et al: Deregulated expression of miR-29a-3p, miR-494-3p and miR-660-5p affects sensitivity to tyrosine kinase inhibitors in CML leukemic stem cells. Oncotarget 8: 49451-49469, 2017.

28. Welten SM, Bastiaansen AJ, de Jong RC, de Vries MR, Peters EA, Boonstra MC, Sheikh SP, La Monica N, Kandimalla ER and Quax PH: Inhibition of 14q32 MicroRNAs miR-329, miR-487b, miR-494, and miR-495 increases neovascularization and blood flow recovery after ischemia. Circ Res 115: 696-708, 2014.

29. Yao R, Feng WT, Xu LJ, Zhong XM, Liu H, Sun Y and Zhou LL: DUXAP10 regulates proliferation and apoptosis of chronic myeloid leukemia via PTEN pathway. Eur Rev Med Pharmacol Sci 22: 4934-4940, 2018.

30. Sun G, Lu Y, Li Y, Mao J, Zhang J, Jin Y, Li Y, Sun Y, Liu L and $\mathrm{Li}$ L: miR-19a protects cardiomyocytes from hypoxia/reoxygenation-induced apoptosis via PTEN/PI3K/p-Akt pathway. Biosci Rep 37, 2017. 
31. Liu L, Yan X, Wu D, Yang Y, Li M, Su Y, Yang W, Shan Z, Gao Y and Jin Z: High expression of Ras-related protein $1 \mathrm{~A}$ promotes an aggressive phenotype in colorectal cancer via PTEN/FOXO3/CCND1 pathway. J Exp Clin Cancer Res 37: 178, 2018.

32. Zhang J, Li L, Peng Y, Chen Y, Lv X, Li S, Qin X, Yang H, Wu C and Liu Y: Surface chemistry induces mitochondria-mediated apoptosis of breast cancer cells via PTEN/PI3K/AKT signaling pathway. Biochim Biophys Acta 1865: 172-185, 2018.

33. Pero-Gascon R, Sanz-Nebot V, Berezovski MV and Benavente F: Analysis of circulating microRNAs and their post-transcriptional modifications in cancer serum by on-line solid-phase extraction-capillary electrophoresis-mass spectrometry. Anal Chem 90: 6618-6625, 2018.

34. Livak KJ and Schmittgen TD. Analysis of relative gene expression data using real-time quantitative PCR and the 2(-Delta Delta C(T)) method. Methods 25: 402-408, 2001.

35. Gossack-Keenan KL and Kam AJ: Toxic shock syndrome: Still a timely diagnosis. Pediatr Emerg Car, 2017. (Epub ahead of print).

36. Zhang M, Zou L, Feng Y, Chen YJ, Zhou Q, Ichinose F and Chao W: Toll-like receptor 4 is essential to preserving cardiac function and survival in low-grade polymicrobial sepsis. Anesthesiology 121: 1270-1280, 2014

37. Krome S: MikroRNA im septischen Schock verändert. Anästhesiol Intensivmed Notfallmed Schmerzther 51: 654-654, 2016.

38. Geng L, Zhang T, Liu W and Chen Y: miR-494-3p modulates the progression of in vitro and in vivo Parkinson's disease models by targeting SIRT3. Neurosci Lett 675: 23-30, 2018.
39. Wang Y, Ouyang M, Wang Q and Jian Z: MicroRNA-142-3p inhibits hypoxia/reoxygenationinduced apoptosis and fibrosis of cardiomyocytes by targeting high mobility group box 1 . Int J Mol Med 38: 1377-1386, 2016

40. Li Y, Wen S, Yao X, Liu W, Shen J, Deng W, Tang J, Li C and Liu K: MicroRNA-378 protects against intestinal ischemia/reperfusion injury via a mechanism involving the inhibition of intestinal mucosal cell apoptosis. Cell Death Dis 8: e3127, 2017.

41. Zheng HZ, Fu XK, Shang JL, Lu RX, Ou YF and Chen CL: Ginsenoside Rg1 protects rat bone marrow mesenchymal stem cells against ischemia induced apoptosis through miR-494-3p and ROCK-1. Eur J Pharmacol 822: 154-167, 2018.

42. Su S, Luo, Liu X, Liu J, Peng F, Fang C and Li B: miR-494 up-regulates the PI3K/Akt pathway via targetting PTEN and attenuates hepatic ischemia/reperfusion injury in a rat model. Biosci Rep 37, 2017.

43. Zhu H, Xie R, Liu X, Shou J, Gu W, Gu S and Che X: MicroRNA-494 improves functional recovery and inhibits apoptosis by modulating PTEN/AKT/mTOR pathway in rats after spinal cord injury. Biomed Pharmacother 92: 879-887, 2017.

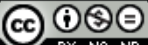

This work is licensed under a Creative Commons Attribution-NonCommercial-NoDerivatives 4.0 International (CC BY-NC-ND 4.0) License. 